\title{
It's Time to Pay Attention to Attention in Aging
}

\author{
Jill McGaughy and Howard Eichenbaum \\ Laboratory of Cognitive Neurobiology, Department of Psychology, Boston University, Boston, Massachusetts 02215, USA
}

The majority of animal models of age-related cognitive decline focus on the well-known loss of memory and the associated deterioration of medial temporal lobe function (for review, see Gallagher and Rapp 1997). However, converging data show that normal aging also results in loss of attentional capacity, both in humans (Parasuraman and Giambra 1991; Greenwood et al. 1997; Berardi et al. 2001) and in rats (Jones et al. 1995; McGaughy and Sarter 1995; Muir et al. 1999), indicating deterioration beyond the temporal lobe. Typically the observed effects of aging on attention are modest, and deficits are apparent only under circumstances of high attentional demands, both in humans (Parasuraman et al. 1987; Parasuraman and Giambra 1991; Mouloua and Parasuraman 1995) and in rats (McGaughy and Sarter 1995; Muir et al. 1999). However, in this issue of Learning \& Memory, Barense et al. (2002) show that one aspect of attentional function may be highly sensitive to the effects of aging, and they suggest a neuroanatomical basis for the attentional component of cognitive aging.

Whereas the previous studies of attention have focused on the ability of aged animals to attend to stimuli that are temporally (McGaughy and Sarter 1995) or spatially unpredictable (Jones et al. 1995; Muir et al. 1999), Barense and colleagues instead explored the capacity of aged rats to redirect or shift attention to a previously irrelevant perceptual dimension as they perform a series of sensory discrimination problems. Their experiment was based on a protocol developed for the study of prefrontal functions in humans (Downes et al. 1989) and then modified for monkeys and rats. In this task, subjects are initially trained to discriminate between pairs of stimuli, each of which is composed of two distinct perceptual dimensions, but only one of these dimensions predicts reinforcement. The learning of novel discriminations is facilitated when the relevant stimulus dimension remains constant (an intradimensional shift [IDS]), allowing the formation of an attentional set. Learning is slower when reinforcement contingencies within the relevant dimension are reversed and greatly impeded when attention must be shifted to the previously irrelevant dimension (an extradimensional shift [EDS]). In monkeys, the lateral prefrontal cortex is required for switching attention to the alternate stimulus dimension, the EDS, but not the initial

${ }^{1}$ Corresponding author.

E-MAIL hbe@bu.edu; FAX (617) 353-1414.

Article and publication are at http://www.learnmem.org/cgi/doi/ $10.1101 / \mathrm{lm} .52902$. discrimination, IDS, or within-dimension reversal learning (Dias et al. 1996a,b, 1997). Similarly, in rats, the medial prefrontal cortex is required for EDS, not the initial discrimination, IDS, or reversal (Birrell and Brown 2000). These studies provide evidence that a distinct prefrontal area mediates the capacity to switch attention to a new stimulus dimension, and this area is functionally homologous across species.

Barense and colleagues applied this protocol to aged rodents and found that aged rats are impaired in EDS, but not initial discrimination or IDS (see more on reversal learning below). Although these subjects were also impaired in the Morris water maze, there was no correlation with the spatial learning deficit and performance in EDS. Comparison of these findings with the lesion studies indicates that aging results in a loss of medial (lateral in primates) prefrontal function, and that this age-associated functional loss is independent of hippocampal dysfunction that underlies the deficits in the water maze (Morris et al. 1982; Gallagher and Holland 1992).

These findings are remarkably similar to the pattern of impairments in attentional set-shifting in humans. Deficits in EDS appear in humans in their seventies but not in their fifties, and these normal elderly subjects perform similarly to patients with circumscribed prefrontal damage (Owen et al. 1991). Furthermore, elderly humans showed normal performance in learning the initial discrimination, in IDS, and in reversal learning. In comparison, humans with medial temporal lobe damage were not impaired on any aspect of this task. The present findings on rodents parallel these data, and together show across species the selectivity of the effect of aging on attentional set-shifting, strongly implying the involvement of the frontal lobe and not the temporal lobe in this type of attention.

In addition, Barense and colleagues described a subset of aged rats that were impaired in reversal learning. Although all aged rats with deficits in reversal were also impaired in EDS, a subset of rats with EDS deficits had no impairment in reversal. In nonhuman primates (Dias et al. 1996a,b, 1997) and in rats (Brown and Bowman 2002), deficits in reversal learning, but not initial discrimination learning, IDS, or EDS, were found in animals with damage to the orbitofrontal cortex. This would indicate that the aged rats with reversal impairments had degeneration in the orbitofrontal cortex, in addition to the deterioration of medial prefrontal cortex. This interpretation may be explained by

LEARNING \& MEMORY 9:151-152 @ 2002 by Cold Spring Harbor Laboratory Press ISSN1072-0502/02 \$5.00

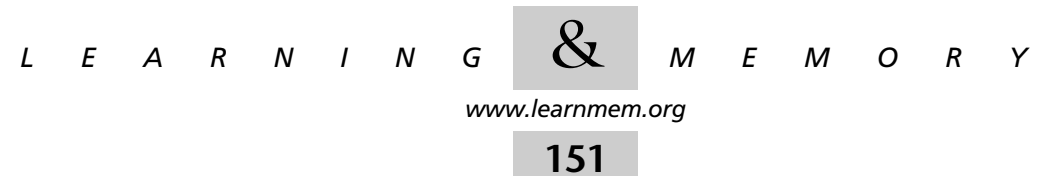


recent data from humans indicating that age-associated degeneration of the orbitofrontal cortex occurs later than degeneration of other prefrontal cortical areas (Salat et al. 2001). If neurological degeneration within medial frontal damage precedes orbitofrontal damage in rats, it should be expected that deficits in EDS precede the impairment in reversal learning. Moreover, if reversal deficits correlate with a more progressed state of neurodegeneration, they should not occur in the absence of EDS deficits, just as reported by Barense and colleagues. These findings indicate that age-related functional loss in the rodent cortex closely parallels the course of neurodegeneration found in nonpathological aging in humans.

Although the utility of rodent models of prefrontal cortex remains debatable (Brown and Bowman 2002), the present findings indicate that the IDS/EDS protocol may be useful in elucidating the neurobiological basis of the cognitive deficits associated with nonpathological aging, and may permit a sensitive assessment of age-associated dysfunction in distinct areas of prefrontal cortex in the rodent.

\section{REFERENCES}

Barense, M.D., Fox, M.T., Baxter, M.G. 2002. Learn. Mem. 9(4): 189-199. Berardi, A., Parasuraman, R., and Haxby, J. 2001. Overall vigilance and sustained attention decrements in healthy aging. Exp. Aging Res. 27: 19-39.

Birrell, J. and Brown, V. 2000. Medial frontal cortex mediates perceptual attentional set shifting in the rat. J. Neurosci. 20: 4320-4324.

Brown, V.J. and Bowman, E.M. 2002. Rodent models of prefrontal cortical function. Trends Neurosci. 25: 340-343.

Dias, R., Robbins, T.W., and Roberts, A.C. 1996a. Dissociation in prefrontal cortex of affective and attentional shifts. Nature 380: 69-72.

. 1996b. Primate analogue of the Wisconsin card sorting test: Effects of excitotoxic lesions of the prefrontal cortex in the marmoset. Behav. Neurosci. 110: 872-886.

1997. Dissociable forms of inhibitory control within prefrontal cortex with an analog of the Wisconsin card sort test: Restriction to novel situations and independence from "on-line" processing. $J$. Neurosci. 17: 9285-9297.

Downes, J.J., Roberts, A.C., Sahakian, B.J., Evenden, J.L., Morris, R.G., and Robbins, T.W. 1989. Impaired extra-dimensional shift performance in medicated and unmedicated Parkinson's disease: Evidence for a specific attentional dysfunction. Neuropsychologia 27: 1329-1342.

Gallagher, M. and Holland, P.C. 1992. Preserved configural learning and spatial learning impairments in rats with hippocampal damage. Hippocampus 2: 81-88.

Gallagher, M. and Rapp, P.R. 1997. The use of animal models to study the effects of aging on cognition. Annu. Rev. Psychol. 48: 339-370.

Greenwood, P.M., Parasuraman, R., and Alexander, G.E. 1997. Controlling the focus of spatial attention during visual search: Effects of advanced aging and Alzheimer's disease. Neuropsychology 11: 3-12.

Jones, D.N.C., Barnes, J.C., Kirkby, D.L., and Higgins, G.A. 1995. Age-associated impairments in a test of attention: Evidence for involvement of cholinergic systems. J. Neurosci. 15: 7282-7292.

McGaughy, J. and Sarter, M. 1995. Behavioral vigilance in rats: Task validation and effects of age, amphetamine and benzodiazepine receptor ligands. Psychopharmacology 117: 340-357.

Morris, R.G., Garrud, P., Rawlins, J.N., and O'Keefe, J. 1982. Place navigation impaired in rats with hippocampal lesions. Nature 297: 681-683.

Mouloua, M. and Parasuraman, R. 1995. Aging and cognitive vigilance: Effects of spatial uncertainty and event rate. Exp. Aging Res. 21: $17-32$.

Muir, J.L., Fischer, W., and Bjorklund, A. 1999. Decline in visual attention and spatial memory in aged rats. Neurobiol. Aging 20: 605-615.

Owen, A.M., Roberts, A.C., Polkey, C.E., Sahakian, B.J., and Robbins, T.W. 1991. Extra-dimensional versus intra-dimensional set-shifting performance following frontal lobe excisions, temporal lobe excisions or amygdalohippocampectomy in man. Neuropsychologia 29: 993-1006

Parasuraman, R. and Giambra, L. 1991. Skill development in vigilance effects of event rate and age. Psychol. Aging 6: 155-169.

Parasuraman, R., Warm, J.S., and Dember, W.N. 1987. Vigilance: Taxonomy and utility. In Ergonomics and human factors (eds. L.S. Mark et al.), pp. 11-32. Springer, New York.

Salat, D.H., Kaye, J.A., and Janowsky, J.S. 2001. Selective preservation and degeneration within the prefrontal cortex in aging and Alzheimer's disease. Arch. Neurol. 58: 1403-1408. 


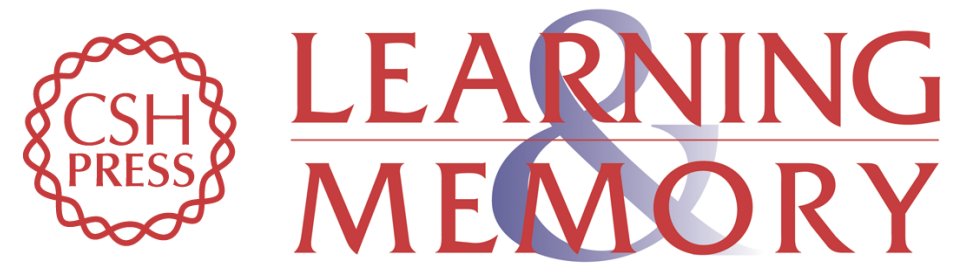

\section{It's Time to Pay Attention to Attention in Aging}

Jill McGaughy and Howard Eichenbaum

Learn. Mem. 2002, 9:

Access the most recent version at doi:10.1101/lm.52902

References This article cites 19 articles, 3 of which can be accessed free at: http://learnmem.cshlp.org/content/9/4/151.full.html\#ref-list-1

License

Email Alerting Receive free email alerts when new articles cite this article - sign up in the box at the Service top right corner of the article or click here. 